\title{
Effect of metoclopramide on nosocomial pneumonia in patients with nasogastric feeding in the intensive care unit
}

M. Nassaji, ${ }^{1}$ R. Ghorbani, ${ }^{2}$ M. Frozeshfard ${ }^{3}$ and F. Mesbahian ${ }^{4}$

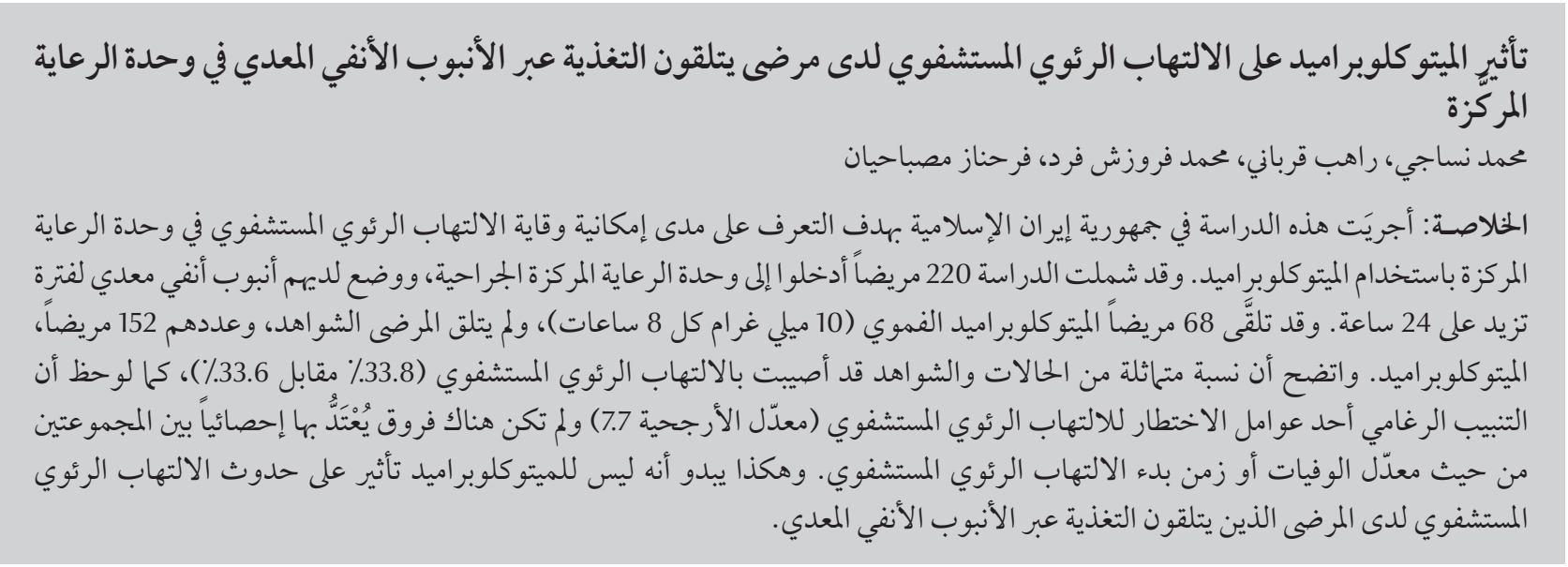

ABSTRACT This study in the Islamic Republic of Iran aimed to determine whether metoclopramide can prevent nosocomial pneumonia in the intensive care unit (ICU). Of 220 patients admitted to the surgical ICU who had a nasogastric tube for more than 24 hours, 68 case patients received oral metoclopramide (10 mg every 8 hours) and 152 control patients did not. Similar proportions of cases and controls developed nosocomial pneumonia (33.8\% versus 33.6\%). Endotracheal intubation was a risk factor for nosocomial pneumonia (odds ratio 7.70). There were no significant differences between groups in mortality rate or time of onset of nosocomial pneumonia. Metoclopramide appears to have no effect on the development of nosocomial pneumonia with nasogastric feeding.

Effets du métoclopramide sur la pneumonie nosocomiale chez les patients alimentés par sonde nasogastrique en service de soins intensifs

RÉSUMÉ L'objectif de cette étude conduite en République islamique d’Iran était de déterminer si le métoclopramide permettait de prévenir la pneumonie nosocomiale en service de soins intensifs. Sur 220 patients admis dans l'unité de soins intensifs en chirurgie, auxquels une sonde nasogastrique avait été posée pendant plus de 24 heures, 68 cas se sont vu administrer du métoclopramide par voie orale (10 mg toutes les 8 heures) et 152 patients témoins n'ont rien reçu. Des proportions similaires de cas et de patients témoins ont développé une pneumonie nosocomiale (33,8 \% contre 33,6\%). L'intubation endotrachéale constituait un risque de pneumonie nosocomiale (odds ratio 7,70). Aucune différence significative n'a été observée entre les deux groupes en termes de taux de mortalité ou de moment de la survenue de la pneumonie nosocomiale. II semble que le métoclopramide n'ait aucun effet sur l'apparition de la pneumonie nosocomiale chez les patients alimentés par sonde nasogastrique.

${ }^{1}$ Department of Infectious Diseases, Fatemieh Hospital; ${ }^{2}$ Department of Social Medicine; ${ }^{3}$ Department of Anaesthesiology, Amir Hospital; ${ }^{4}$ Emergency Ward, Semnan University of Medical Sciences, Semnan, Islamic Republic of Iran (Correspondence to M. Nassaji: hnassaji@yahoo.com). Received: 25/12/07; accepted: 05/05/08 


\section{Introduction}

Nosocomial pneumonia (NP) is an inflammation of the lung parenchyma that develops 48-72 hours after admission to hospital due to infectious agents not incubating at the time of admission [1]. Despite an increased understanding of its pathogenesis and advances in diagnosis and treatment, the risk, cost, morbidity and mortality associated with NP remain unacceptably high. It is one of the leading causes of extended hospital stays and death from hospitalacquired infections [2].

Nasogastric tube feeding has been shown to be a risk factor for development of NP in hospital, possibly due to aspiration of pathogenic microorganisms that have colonized the gastrointestinal tract (GIT) and oropharynx $[3,4]$. The mechanism is believed to be a modification to gastric $\mathrm{pH}$ that causes bacterial overgrowth in the stomach together with an increase in gastric volume during nasogastric tube feeding that facilitates reflux of gastric contents into the pharynx leading to aspiration of gastric contents, tracheal colonization and eventually pneumonia in some patients [5-7]. The physical presence of the nasogastric tube across the lower oesophageal sphincter may impair contraction, prevent sphincter closure and promote reflux of gastric contents $[8,9]$.

Several drugs have been used to prevent oesophageal reflux of gastric contents in patients suffering from gastric reflux. Metoclopramide is a prokinetic agent that results in coordinated contraction and enhances transit in the GIT. Its effects are confined largely to the upper GIT. It increases lower oesophageal sphincter tone and stimulates antral and small intestine contraction, but has no effect on oesophageal peristalsis [10]. This makes it a promising agent for reducing reflux and the risk of NP in the intensive care unit (ICU).

Because there are a few studies that have evaluated the role of antireflux drugs in the prevention of NP, we designed this study to evaluate the possible effect of metoclopramide on ICU patients receiving nasogastric feeding.

\section{Methods}

In this double-blind clinical trial, all adult patients admitted to a 10-bed surgical ICU in Semnan, Islamic Republic of Iran, were eligible for enrolment if they required placement of a nasogastric tube for more than 24 hours. All patients were given standard ICU care with no special measures to reduce the incidence of NP. Patients who already had pneumonia, had received a nasogastric tube before ICU admission or who were discharged or died within 48 hours after admission were excluded.

The study was approved by the Semnan University of Medical Sciences ethics committee. Informed written consent was obtained from all patients (where possible) or their next-of-kin in the case of unconscious patients.

Patients were randomized into 2 groups with the first patient entering the ICU being assigned to the case group and the following 2 patients to the control group and so on. One group (case patients) received metoclopramide (10 mg every 8 hours) through the nasogastric tube. The other group (control patients) did not receive metoclopramide. We recorded the baseline characteristics of the patients, including age, sex, primary diagnosis, tracheal intubation and outcome (dead or alive). Metoclopramide was continued daily for a maximum of 5 days unless the patient developed NP or died.

Baseline complete blood count and chest X-ray were done. Patients were examined daily by the same infectious diseases specialist for development of NP. Pneumonia was defined as the presence of all of the following criteria: axillary temperature $>37.5^{\circ} \mathrm{C}$, leukocytosis (white blood cell count $>11000$ cells/L), increase in tracheal secretions $\left(>0.4 \mathrm{~cm}^{3} / \mathrm{h}\right)$ and new infiltrate on the chest radiograph or progression of an existing infiltrate. Patients were followed until discharge from the ICU or death. NP that developed before 5 days was defined as early-onset NP and $\geq 5$ days as late-onset NP.

We analysed the data using chisquared, Fisher exact, unpaired Student $t$-test and logistic regression using SPSS software, version 11.5.

\section{Results}

A total of 220 patients were included over a 16-month period; 68 received metoclopramide. The characteristics of the patients are shown in Table 1. The mean age of cases was 41.5 (standard deviation 23.9) years and of controls was 46.4 (SD 24.8) years. The most common underlying problem in both groups was neurosurgical problems. The mean time of hospitalization in cases was 9.0 days and in the controls was 10.5 days.

Almost the same proportion of cases (23/68, 33.8\%) and controls (51/152, $33.6 \%)$ developed pneumonia $(P$ $=0.969)$. Other findings are shown in Table 2. There were no significant differences between the case and control groups in the proportion of patients who died (27.9\% versus 38.8\% respectively) $(P=0.119)$. Among 143 patients with tracheal intubation, similar proportions of cases $(18 / 37,48.6 \%)$ and controls (49/106, 46.2\%) developed NP. Early-onset NP developed in 23 cases (33.8\%) and 39 controls (25.8\%) $(P=0.014)$.

To adjust for the effect of metoclopramide in the development of NP, stepwise logistic regression was used. The only variables remaining significant after regression analysis were neurosurgical problems and intubation (Table 3). Patients having neurosurgery had a greater risk of developing NP compared with patients with laparotomy or other procedures [odds ratio (OR) 2.88; $95 \%$ 


\begin{tabular}{|c|c|c|c|c|c|c|c|}
\hline $\begin{array}{l}\text { Table 1 Character } \\
\text { patients }\end{array}$ & f case & tients & receivi & metoclo & & de and co & ntrol \\
\hline Factor & Cases & $=68)$ & Contro & $(n=152)$ & df & Test & $P$-value \\
\hline & No. & $\%$ & No. & $\%$ & & statistic & \\
\hline Age (years) & & & & & & & \\
\hline$<30$ & 30 & 44.1 & 50 & 32.9 & & & \\
\hline $30-39$ & 8 & 11.8 & 19 & 12.5 & 3 & 3.283 & 0.350 \\
\hline $40-49$ & 5 & 7.4 & 9 & 5.9 & & & \\
\hline$\geq 50$ & 25 & 36.7 & 74 & 48.7 & & & \\
\hline Sex & & & & & & & \\
\hline Female & 19 & 27.9 & 57 & 37.5 & 1 & 1.898 & 0.168 \\
\hline Male & 49 & 72.1 & 95 & 62.5 & & & \\
\hline Tracheal intubati & & & & & & & \\
\hline No & 31 & 45.6 & 46 & 30.3 & 1 & 4.850 & 0.028 \\
\hline Yes & 37 & 54.4 & 106 & 69.7 & & & \\
\hline Underlying probl & & & & & & & \\
\hline Neurosurgery & 49 & 72.1 & 70 & 46.1 & & & \\
\hline Laparotomy & 11 & 16.2 & 30 & 19.7 & 2 & 14.873 & 0.001 \\
\hline Other & 8 & 11.8 & 52 & 34.2 & & & \\
\hline
\end{tabular}

$d f=$ degrees of freedom.

confidence interval (CI): 1.38-6.03]. The risk of NP in patients with tracheal intubation was nearly 8 times greater than in those without intubation (OR 7.70; 95\% CI: 3.24-18.27).

\section{Discussion}

The risk of aspiration of gastric contents into the lower airways is believed to be related to the presence of gastroesophageal reflux. In studies evaluating the efficacy of metoclopramide on prevention of acid aspiration it has been shown that it decreases the volume of gastric contents to less than $20-25 \mathrm{~mL}$ in $62 \%-87 \%$ of patients, without any significant effect on gastric $\mathrm{pH}$. It also increases the lower oesophageal sphincter pressure [11-14]. Several studies have demonstrated that nasogastric tube feeding increases gastric volume and pressure and bacterial contamination with Gram-negative bacilli. It also disrupts the oesophagogastric

\begin{tabular}{|c|c|c|c|c|c|c|c|}
\hline \multirow[t]{3}{*}{ Dependent variable } & \multicolumn{4}{|c|}{ Study group } & \multirow[t]{3}{*}{ df } & \multirow{3}{*}{$\begin{array}{c}\text { Test } \\
\text { statistic }\end{array}$} & \multirow[t]{3}{*}{$P$-value } \\
\hline & \multicolumn{2}{|c|}{ Case $(n=68)$} & \multicolumn{2}{|c|}{ Control $(n=152)$} & & & \\
\hline & No. & $\%$ & No. & $\%$ & & & \\
\hline \multicolumn{8}{|l|}{ Patient outcome } \\
\hline Died & 19 & 27.9 & 59 & 38.8 & 1 & 2.428 & 0.119 \\
\hline Survived & 49 & 72.1 & 93 & 61.2 & & & \\
\hline \multicolumn{8}{|l|}{ Developed pneumonia } \\
\hline No & 45 & 66.2 & 101 & 66.4 & 1 & 0.002 & 0.969 \\
\hline Yes & 23 & 33.8 & 51 & 33.6 & & & \\
\hline \multicolumn{8}{|l|}{$\begin{array}{l}\text { Time of onset of } \\
\text { pneumonia }\end{array}$} \\
\hline$<5$ & 23 & 33.8 & 39 & 25.8 & 1 & - & 0.014 \\
\hline$\geq 5$ & 0 & 0.0 & 12 & 7.8 & & & \\
\hline
\end{tabular}

$d f=$ degrees of freedom. barrier, promoting transfer of gastric microorganisms into the pharynx and trachea, and is associated with a severalfold increase in the risk of developing NP $[4,15,16]$. We hypothesized that metoclopramide, by reducing the reflux of gastric contents into the oesophagus and nasopharynx, may also help to reduce the frequency of NP.

Gastroesophageal reflux is a very common phenomenon in critically ill patients and is probably related to the presence of the nasogastric tube and mechanical ventilation. Manchikanti et al. concluded that the addition of metoclopramide to the preanaesthetic preparation of patients would be effective for prophylaxis of aspiration pneumonia [16]. Our findings showed that treatment with metoclopramide in critically ill patients had no effect on the proportion of patients who developed NP or on the mortality rate. In agreement with our finding, Yavagal et al. concluded that metoclopramide did not decrease the frequency of developing NP or the mortality rate [17].

Previous studies have demonstrated that the risk of NP associated with nasogastric tube feeding was highest in patients receiving mechanical ventilation. Positive gastric pressure during ventilation may increase oesophageal reflux $[15,18]$. In our study the risk of NP in patients with tracheal intubation was 7.70 times greater than in those without intubation. We found that metoclopramide had no preventive effect in these subgroups.

There was no significant difference between the case and control groups in the timing of onset of NP, comparing late ( $\geq 5$ days) and early-onset NP $(<5$ days). In contrast, Yavagal et al. concluded that metoclopramide delayed the development of NP by an average of 1.5 days [17]. Most studies that have shown a preventive effect of metoclopramide were in patients having elective surgery, i.e. those who were not critically ill $[11,12,16]$. There are many problems 


$\begin{aligned} & \text { Table } 3 \text { Logistic regression analysis of the effect of underlying problem and } \\
& \text { tracheal intubation on the risk of nosocomial pneumonia }\end{aligned}$
\begin{tabular}{lcccccc}
\hline Variables & $\begin{array}{c}\text { Beta } \\
\text { coefficient }\end{array}$ & SE & P-value & OR & $\begin{array}{c}\mathbf{9 5 \%} \text { Cl } \\
\text { for OR }\end{array}$ \\
Underlying problem & & & & & & \\
Neurosurgery & 1.06 & 0.38 & 0.002 & 2.88 & $1.38-6.03$ \\
Laparotomy & -0.36 & 0.6 & 0.005 & 0.70 & $0.22-2.25$ \\
Other & - & - & 0.548 & - & \\
Tracheal intubation & 2.04 & 0.44 & $<0.001$ & 7.70 & $3.24-18.27$ \\
Constant & -2.79 & 0.51 & $<0.001$ & - & - \\
\hline
\end{tabular}

$S E=$ standard error; $O R=$ odds ratio; $C I=$ confidence interval.

in critically ill patients that may interfere with the preventive effect of this drug: decreased GIT perfusion impairs absorption; the autonomic effect of stress or pain impairs GIT motility; and concurrent use of other drugs (i.e. opioids, dopamine) impairs motility. We used the oral form of the drug, which may explain its lack of effectiveness.
Apart from regurgitation of gastric contents, another postulated mechanism for the development of NP is migration of bacteria along the tube from the stomach to the upper airways [4]. Drugs that reduce gastroesophageal reflux will not have any effect on this mechanism.

In conclusion, oral metoclopramide in the dose used in this study $(10 \mathrm{mg}$ every 8 hours) did not reduce the risk of developing NP in ICU patients with nasogastric feeding

Because of the small numbers involved, the odds ratios were quite wide, especially for intubation, and the study therefore did not have sufficient power. We did not perform gastric motility studies, oesophageal $\mathrm{pH}$ manometery or measurement of metoclopramide levels in plasma and therefore we cannot conclude that metoclopramide failed to prevent gastroesophageal reflux. Another limitation of the study was that more case than control patients had neurosurgical problems and increased intracranial pressure is associated with impaired gastric emptying. Studies that monitor the metoclopramide level in plasma, that use a higher dose or the injection form of metoclopramide and that have a larger sample size are recommended.

\section{References}

1. Stransbaugh L. Nosocomial respiratory infections. In: Mandell GL, Bennett JE, Dolin R, eds. Principles and practice of infectious diseases. Philadelphia, Churchill Livingstone, 2005:2362-6.

2. Fleming CA, Balaguera HU, Craven DE. Risk factors for nosocomial pneumonia. Focus on prophylaxis. Medical clinics of North America, 2001, 85:1545-63.

3. Fishman J et al. Nosocomial respiratory infections and Gramnegative pneumonia. In: Fishman A et al., eds. Manual of pulmonary diseases and disorders. New York, McGraw-Hill, 2002:734-53.

4. Torres A et al. Stomach as a source of colonization of the respiratory tract during mechanical ventilation: association with ventilator-associated pneumonia. European respiratory journal, 1996, 9:1729-35.

5. Apte NM et al. Gastric colonization and pneumonia in intubated critically ill patients receiving stress ulcer prophylaxis: a randomized, controlled trial. Critical care medicine, 1992, 20:590-3.

6. Torres A et al. Gastric and pharyngeal flora in nosocomial pneumonia acquired during mechanical ventilation. American review of respiratory diseases, 1993, 148:352-7.

7. Heyland D, Mandell LA. Gastric colonization by gram-negative bacilli and nosocomial pneumonia in the intensive care unit patients. Evidence for causation. Chest, 1992, 101:187-93.

8. Ostendorf U, Ewig S, Torres A. Nosocomial pneumonia. Current opinion in infectious diseases, 2006, 19:327-38.

9. Joshi N, Localio R, Hamory BH. A predictive risk index for nosocomial pneumonia in the intensive care unit. American journal of medicine, 1992, 93:135-42.
10. Pasrich PJ. Treatment of disorders of bowel motility and water flux. In: Brunton L, eds. Goodman and Gilman's the pharmacological basis of therapeutics. New York, McGraw-Hill, 2006:985-6.

11. Manchikanti L et al. Bicitra (sodium citrate) and metoclopramide in outpatient anesthesia for prophylaxis against aspiration pneumonitis. Anesthesiology, 1985, 63:903-10.

12. Orr DA et al. Effects of omeperazole, with and without metoclopramide, in elective obstetric anaesthesia. Anaesthesia, 1993, 48:114-9.

13. Jooste CA, Mustoe J, Collee G. Metoclopramide improves gastric motility in critically ill patients. Intensive care medicine, 1999, 25:464-8.

14. El Solh AA, Saliba R. Pharmacologic prevention of aspiration pneumonia: a systematic review. American journal of geriatric pharmacotherapy, 2007, 5:352-62.

15. Inglis TJ et al. Gastroduodenal dysfunction and bacterial colonization of the ventilated lung. Lancet, 1993, 341:911-3.

16. Manchikanti L et al. Ranitidine and metoclopramide for prophylaxis of aspiration pneumonitis in elective surgery. Anesthesia and analgesia, 1984, 63:903-10.

17. Yavagal DR, Karnad DR, Oak JL. Metoclopramide for preventing pneumonia in critically ill patients receiving enteral tube feeding: a randomized controlled trial. Critical care medicine, 2000, 28:1408-11.

18. Orozco Levi $M$ et al. Semirecumbent position protects from pulmonary aspiration but not from gastroesophageal reflux in mechanically ventilated patients. American journal of respiratory and critical care medicine, 1995, 152:1387-90. 